\title{
Sickle-Cell Disease Co-Management, Health Care Utilization, and Hydroxyurea Use
}

\author{
Nancy Crego, PhD, Christian Douglas, DrPh, Emily Bonnabeau, BA, \\ Marian Earls, MD, Kern Eason, MBA, Elizabeth Merwin, PhD, Gary Rains, BA, \\ Paula Tanabe, PhD, MSN, MPH, and Nirmish Shah, MD
}

Background: Sickle-cell disease (SCD) causes significant morbidity, premature mortality, and high disease burden, resulting in frequent health care use. Comanagement may improve utilization and patient adherence with treatments such as Hydroxyurea. The purpose of this study was to describe acute-care utilization in Medicaid-enrolled patients with SCD, patient factors associated with comanagement, and adherence to Hydroxyurea.

Methods: Data from 2790 patients diagnosed with SCD, age 1 to 65+ years, enrolled at least 1 month in North Carolina Medicaid between March 2016 and February 2017, were analyzed. Outpatient visits were categorized as primary care, hematologist, and nonhematologist specialist. Nurse practitioners or physician assistants with unidentified specialty type or family practice were categorized separately. Comanagement was defined as a minimum of 1 primary care and 1 hematologist visit/patient during the study period.

Results: There were notable age-related differences in utilization of health care services. Only $34.82 \%$ of the sample was comanaged. Comanagement was higher in the 1-to-9-year-old (44.88\%) and 10-to-17-year-old groups $(39.22 \%)$ versus the 31-to-45-year-old $(30.26 \%)$ and $65+$-year-old (18.75\%) age groups. Age had the greatest influence $(\mathrm{AUC}=0.599)$ on whether or not a patient was comanaged. Only a third of the sample (32.24\%) had at least 1 Hydroxyurea (HU) prescription. Age was the most predictive factor of good HUadherence $(\mathrm{AUC}=\mathbf{0 . 6 5 0 3})$. Prediction by comanagement was minimal with an $\mathrm{AUC}=0.5615$.

Conclusion : Comanagement was a factor in predicting HUadherence, but further studies are needed to identify the frequency and components of comanagement needed to increase adherence and reduce acute care utilization. (J Am Board Fam Med 2020;33:91-105.)

Keywords: Child Health, Emergency Departments, Hematology, Hospitalization, Hydroxyurea, Medicaid, Minority Health, North Carolina, Primary Health Care, Sickle-Cell Anemia, Vulnerable Populations

Sickle-cell disease (SCD) is a genetic disorder and the most common rare blood disease in the United States. ${ }^{1}$ Patients suffer from complications, includ-

This article was externally peer reviewed.

Submitted 18 April 2019; revised 21 August 2019; accepted 25 August 2019.

From Duke University School of Nursing, Durham, NC (NC, CD, EB, PT); Community Care of North Carolina, Raleigh, NC (ME, KE); University of Texas College of Nursing, Austin, TX (EM); Duke University School of Medicine, Durham, NC (GR); Duke University Medical Center, Durham, NC (NS)

Funding: Supported by National Heart, Lung and Blood Institute (R18 RHS024501A).

Conflict of interest: none declared.

Corresponding author: Nancy Crego, PhD, Duke University School of Nursing, 307 Trent Drive, Durham, NC 27710 (E-mail: nancy.crego@duke.edu). ing but not limited to stroke, acute chest syndrome, and severe painful crisis that contributes to morbidity and premature mortality. Individuals also suffer from significant disease burden, often resulting in a high number of hospitalizations, readmissions, emergency department (ED) visits, and other associated costs to the health care system. In 2006 people with SCD had an estimated 232,382 ED visits, 68,410 hospitalizations from the $\mathrm{ED}$, accounting for an estimated $\$ 2.4$ billion dollars. ${ }^{2}$ In 2010, SCD was associated with the highest 30-day readmission rate $(31.9 \%)$ among all diagnoses excluding cancer and cancer-related conditions. ${ }^{3}$ Other national data representing about $1 / 3$ of the SCD population found a similar 30 -day readmis- 
sion rate of $33.4 \%$ and 14 -day readmission rate of $22.1 \% .{ }^{4}$ Extremely high ED use has also been well described. ${ }^{5,6}$ In a prospective cohort study of SCD, health care utilization was examined in 3 EDs over 2 years and found 342 unique patients had a total of $2934 \mathrm{ED}$ visits. ${ }^{6}$ Understanding there is significant health care utilization due to disease severity, there has been an increasing effort to leverage outpatient primary care providers (PCPs) using a care model in which hematology specialists and PCPs partner to comanage SCD. Primary care and outpatient management using evidence-based guidelines can improve disease burden, improve patient outcomes, and prevent the need for ED visits and inpatient hospitalizations. ${ }^{7-10}$

The National Heart Lung and Blood Institute (NHLBI) published the Evidence-Based Management of SCD Report, in 2014. This comprehensive guide consists of health maintenance and prevention information, including the use of hydroxyurea (HU). HU is an oral agent found to reduce the median number of SCD pain episodes per year by $44 \%$, but is historically underutilized. ${ }^{11}$ Only $32 \%$ of general internists and $35 \%$ of pediatricians report feeling comfortable caring for SCD patients. ${ }^{12}$ In a study of 129 PCPs with greater than 10 years (median) since graduating from medical school, $80 \%$ reported relying on knowledge gained in residency when deciding how to manage SCD patients and $68 \%$ did not regularly communicate with other providers regarding their SCD patients. ${ }^{12}$ In a survey of 53 primary care physicians in North Carolina, $65 \%$ indicated they are already comfortable comanaging HU prescriptions with a SCD specialist. ${ }^{9}$ More specific to family physicians, in a large survey of over 1000 family physicians, comfort level for managing patients with SCD was low (20\%); however, $80 \%$ and $68 \%$ of respondents indicated they would be willing to comanage pediatric and adults patients with a SCD specialist. ${ }^{13}$ Thus, a gap exists in the implementation of current evidence based practices in the management of SCD in the ambulatory setting.

As adults with SCD age, they are at risk for developing comorbidities unrelated to SCD. Thus, individuals with SCD are recommended to have both a PCP and a SCD specialist comanage their care. Comanagement is defined as collaborative and coordinated care that is conceptualized, planned, delivered, and evaluated by 2 or more health care providers. Nationally, there is often a lack of providers and comanagement for individuals with SCD is not common practice. ${ }^{11}$ It is possible that comanagement of patients with SCD, in combination with dissemination of evidence based guidelines, could lead to an increased comfort level of family physicians, internists, and pediatricians. Therefore we designed a dissemination and implementation project to promote comanagement between SCD specialists and PCPs. Our team partnered with Community Care North Carolina (CCNC), a statewide primary case management program for North Carolina (NC) Medicaid enrollees. ${ }^{14} \mathrm{CCNC}$ spans 14 community-based primary care networks throughout the state and works collaboratively with physicians and other health care professionals to promote quality-improvement and care-management initiatives. ${ }^{14}$ For the purposes of this project, we defined comanagement as a minimum of $1 \mathrm{PCP}$ and 1 hematologist visit/ patient during the study period. We adapted the NHLBI recommendations into user-friendly tools (health maintenance charts and treatment algorithms) designed specifically for and with the input of PCPs and ED providers, which are easy to access and use. These tools are available on 2 Web sites (sickleemergency.duke.edu and www.communitycarenc.org) as well as via a mobile application (www.scdtoolbox.com).

This article reports baseline Medicaid data from NC before dissemination efforts, including 1) ED encounters and re-encounters within 7, 14, and 30 days, hospitalization and rehospitalization within 7 , 14, and 30 days; 2) PCP, hematologist, nonhematology specialist visits and comanagement (at least 1 PCP and hematologist visit per patient during a 1 year period); and 3) HU prescription fills and adherence. In addition, this article will identify predictors of HU adherence and comanagement for patients insured under Medicaid in NC.

\section{Methods}

\section{Dataset_Medicaid North Carolina}

In fiscal year 2017 almost 2 million people (approximately one fifth of NC's population) were covered by Medicaid; making it the third largest Medicaid population in states that did not expand the program. ${ }^{15}$ In fiscal year 2016 there were 68,583 NC Medicaid providers. ${ }^{15}$ In partnership with CCNC, we obtained a dataset of Medicaid administrative claims of enrollees with a diagnosis of SCD includ- 
ing HbSS, HbSC, and HbS-thalassemia, excluding sickle-cell trait (International Classification of Diseases, [ICD] 10 CM codes: D57.0x, D57.1, D57.2x, D57.8x).

\section{Sample}

Data are reported for a cohort of 2045 patients with a diagnosis of SCD, age 1 to $65+$ years, enrolled at least 12 months in NC Medicaid between March 1, 2016 and February 28, 2017. Table 1 further describes the sample. Institutional Review Board (IRB) approval and waiver of consent were obtained.

\section{Measures}

Emergency Department Encounters and Hospitalization

ED encounters were identified using a CCNCdeveloped logic model that used revenue codes (450 to 452, 456, and 459) and excluding Medicare Part A crossover-inpatient, inpatient, management fee, drug and capitation claim type codes. ED reencounters and rehospitalizations within 7, 14, and 30 days were identified using the time between the date of service listed on the ED or hospital claim and the next date of service in the subsequent claim. Individual ED Reliance (EDR) score was calculated as the total number of ED encounters divided by the total ambulatory visits (outpatient + ED encounters) per enrollee. ${ }^{16,17}$ An EDR of $>0.33$ is a high score. ${ }^{17}$ Inpatient claims were identified using category of service code $(0015,0017,0018,0040$, 0041, 0051, and 0058) and with either a Medicare Part A crossover-inpatient or inpatient claim type.

\section{Outpatient Visits and Comanagement}

Outpatient visits were identified by the Current Procedural Terminology (CPT) code listed on the claim. Outpatient visit types (PCP, hematologists, and nonhematology specialists) were identified using the descriptions from the Medicare Provider/ Supplier to Health Care Provider Taxonomy that matched the billing provider code and the rendering provider code listed on the claim. ${ }^{18}$ Visits were classified into the following categories: 1) PCP (including pediatrician), 2) hematologist (including pediatric hematologists), 3) nonhematology specialist (see Table 2 for the list of nonhematology specialists), and 4) nurse practitioner (NP) or physician assistant $(\mathrm{PA})$ visits. $\mathrm{NP}$ and $\mathrm{PA}$ visits in which a PCP, hematology, or nonhematology specialty was indicated on the claim were included into
Table 1. Demographic Characteristics and Enrollment in CCNC Programs (Sample $=2045)$

\begin{tabular}{|c|c|}
\hline Characteristics & Statistic \\
\hline \multicolumn{2}{|l|}{ Sex, n (\%) } \\
\hline Female & $1162(56.82)$ \\
\hline Male & $883(43.18)$ \\
\hline Age, mean (SD) & $22.87(16.41)$ \\
\hline \multicolumn{2}{|l|}{$\mathrm{N}(\%)$} \\
\hline 1 to 9 years old & $499(24.40)$ \\
\hline 10 to 17 years old & $436(21.32)$ \\
\hline 18 to 30 years old & $537(26.26)$ \\
\hline 31 to 45 years old & $347(16.97)$ \\
\hline 46 to 64 years old & $194(9.49)$ \\
\hline$\geq 65$ years old & $32(1.56)$ \\
\hline $\begin{array}{l}\text { CCNC program months enrolled*, mean } \\
\text { (SD) }\end{array}$ & $10.67(3.43)$ \\
\hline \multicolumn{2}{|l|}{$\begin{array}{l}\text { Dual eligible Medicare and Medicaid, n } \\
(\%)\end{array}$} \\
\hline Yes & $417(20.39)$ \\
\hline No & $1628(79.61)$ \\
\hline \multicolumn{2}{|l|}{ Residence $^{\dagger}, \mathrm{n}(\%)$} \\
\hline Metro & $1558(76.19)$ \\
\hline Non-Metro adjacent to Metro & $440(21.52)$ \\
\hline Non-Metro un-adjacent to Metro & $47(2.30)$ \\
\hline \multicolumn{2}{|l|}{ CCNC network, n (\%) } \\
\hline Access East & $390(19.07)$ \\
\hline Access Care & $180(8.80)$ \\
\hline $\begin{array}{l}\text { Carolina Collaborative Community } \\
\text { Care }\end{array}$ & $125(6.11)$ \\
\hline $\begin{array}{l}\text { Carolina Community Health } \\
\text { Partnership }\end{array}$ & $30(1.47)$ \\
\hline $\begin{array}{l}\text { Community Care Partners of Greater } \\
\text { Mecklenburg }\end{array}$ & $320(15.65)$ \\
\hline $\begin{array}{l}\text { Community Care of Southern } \\
\text { Piedmont }\end{array}$ & $66(3.23)$ \\
\hline $\begin{array}{l}\text { Community Care of Wake/Johnston } \\
\text { Counties }\end{array}$ & $217(10.61)$ \\
\hline $\begin{array}{l}\text { Community Care of Western North } \\
\text { Carolina }\end{array}$ & $20(0.98)$ \\
\hline $\begin{array}{l}\text { Community Care of the Lower Cape } \\
\text { Fear }\end{array}$ & $112(5.48)$ \\
\hline Community Care of the Sandhills & $102(4.99)$ \\
\hline Community Health Partners & $37(1.81)$ \\
\hline Northern Piedmont Community Care & $133(6.5)$ \\
\hline Northwest Community Care Network & $134(6.55)$ \\
\hline Partnership for Community Care & $179(8.75)$ \\
\hline
\end{tabular}

CCNC, Community Care of North Carolina

${ }^{*} \mathrm{CCNC}$ program enrollment is defined as having active full Medicaid coverage and being linked to a medical home.

${ }^{\dagger}$ Residence categories were determined using the United States Department of Agriculture 2013 Rural-Urban Continuum Codes.

the corresponding category. When we were unable to determine if an NP or PA visit provided primary care, hematology, or other specialty care, they were 
Table 2. List of Non-Hematology Specialist by Type and Visit Frequency for Age 1 to $65+($ Sample $N=2045)$

\begin{tabular}{lc}
\hline Specialty Type & Frequency \\
\hline Primary care visits & 6251 \\
Hematology specialty visits & 2792 \\
Non-hematology specialty visits & 8827 \\
Acute care $^{*}$ & 2743 \\
Physician assistant (unidentified specialty or & 1477 \\
$\quad$ family practice) & \\
Nurse practitioner (unidentified specialty or & 1144 \\
family practice) & \\
Unidentifiable (null) & \\
Obstetrician/gynecologist & 458 \\
Other specialty visits & \\
Orthopedic medicine & 383 \\
Ophthalmology/optometry & 377 \\
Surgery & 295 \\
Cardiology & 282 \\
Neurology & 235 \\
Pulmonary & 191 \\
Oncology & 178 \\
Nephrology & 174 \\
Otolaryngology & 161 \\
Anesthesiology & 122 \\
Gastroenterology & 116 \\
Physical and rehabilitation medicine & 103 \\
Foot \& ankle surgery/podiatric medicine & 96 \\
Urology & 91 \\
Psychology & 87 \\
\hline
\end{tabular}

*Acute care visit—a visit that occurred in an out-patient acute setting.

${ }^{\dagger}$ Unidentifiable (Null) category includes office visits with a billing provider code for "multi-specialty" or "single specialty" with no rendering provider information.

${ }^{\ddagger}$ Other specialty visits include outpatient visits not historically linked to SCD care or a frequency of visits within the specialty category $\leq 1 \%$ of the total number of specialty visits. Excludes SCD and general NP or PA visits. Includes addiction medicine, allergy and immunology, anatomic pathology, critical care medicine, dermatology, development behavior, diagnostic radiology, endocrinology, geriatric medicine, infectious disease, special hospital, neonatal-perinatal medicine, neuro-development, rheumatology, sleep medicine, sports medicine, vascular and interventional.

included in the NP or PA unidentified specialty type or family practice. The "Other Specialty" category includes outpatient visits not historically linked to SCD care or with a frequency of $\leq 1 \%$ of the total number of nonhematology specialty visits. If the billing provider or rendering provider code was either missing or did not link to a specific provider type, then those visits were placed in the "Null" category to signify they were unidentifiable. "Acute care visits" signified medical care occurred outside the ED, and were not inpatient stays but occurred in an acute care location. Comanagement is defined as a minimum of 1 PCP and 1 hematologist visit/patient during the study period. Our team discussed this definition at length and agreed this is a bare minimum and comanagement should include more than 1 visit by both the PCP and SCD specialist. However, because comanagement for patients with SCD is so rare, we agreed to examine a bare minimum of 1 visit for each.

\section{HU Prescription Fills and Adherence}

HU claims were identified using the drug name. Only those enrolled in Medicaid for 12 months were included in this analysis. The number of $\mathrm{HU}$ prescriptions filled per enrollee by age group was determined by summing the number of filled HU prescriptions over the study period for each eligible enrollee. The number of HU days supplied is the sum of the days of supply on the prescription (eg, 30 -day supply) in a 12 -month period per person. The duration of $\mathrm{HU}$ treatment days was measured as the number of days between the date of the first HU prescription filled and the last day of the study period. The number of days between breaks in treatment is the sum of days with no HU supplied, divided by the number of gaps (missing next HU prescription fill) per person.

$\mathrm{HU}$ adherence was categorized into 1 of the following: 1) Good-if number of days supplied is $\geq 80 \%$ of duration of HU treatment, 2) Fair or Moderate-if number of days supplied is $60 \%$ to $79 \%$ of duration of HU treatment, 3) Poor-if number of days supplied is $<60 \%$ of duration of HU treatment. ${ }^{19,20}$

\section{Predictor Measures}

Age-related differences in SCD health service utilization have been found in several studies. ${ }^{16,21-24}$ Young adults that are transition aged (16 to 25 years) have particularly high rates of acute (emergency and inpatient) care utilization. ${ }^{23}$ However, 18-to-30-year-olds with SCD have the highest reported rates of acute care encounters per patient per year, before decreasing throughout middle and older ages. ${ }^{4}$ Differences in EDR depending on age have also been previously noted in SCD patients, with highest EDR noted in those transitioning to adulthood. ${ }^{16}$ For this study, patients were categorized into age categories similar to previously published groups. ${ }^{25,26}$ The following groups were uti- 
lized: 1 to 9 years, 10 to 17 years, 18 to 30 years, 31 to 45 years, 46 to 64 years, and $\geq 65$ years. ${ }^{25}$ Gender differences in frequency and intensity of pain have previously been reported. Several studies have found an increased sensitivity and lower tolerance to pain in women and have shown related increased health service utilization. ${ }^{27-29}$ However, prior studies in reporting SCD pain have reported no difference in pain experiences between men and women, but higher health care utilization by men. ${ }^{30,31}$ For this study enrollees were categorized as either male or female. Number of months enrolled in the CCNC network (1 to 12 months) was obtained to account for variations in comanagement and $\mathrm{HU}$ adherence that could be affected by the length of time in the network. Differences in the geographic location of people with SCD have been linked to differences in health-service utilization. ${ }^{32}$ Prior studies indicate that the further away clients with SCD are from clinics, the lower the rate of health service utilization. ${ }^{32,33} \mathrm{In}$ this study patient zip codes were used to categorize the sample by county using the US Department of Agriculture Economic Research Service (ERS) 2013 Rural-Urban Continuum Codes classification to distinguish metropoli$\tan$ (metro) counties by population size and nonmetropolitan (nonmetro) counties by their degree of urbanization and adjacency to metro areas. ${ }^{34}$ This method allows for consideration of regional factors such as proximity to an urban area that may influence utilization of health care services.

\section{Analysis}

Descriptive statistics, means, and standard deviations for interval variables and frequencies and percentages for categorical variables were computed to summarize demographic characteristics of the sample. Inpatient and ambulatory health care and HU utilization were summarized by frequencies, medians, and interquartile ranges (IQRs), due to skewed distributions. Utilization summaries were presented for the overall sample and by 6 age categories. Only those participants age 1 to $65+$ years, who were enrolled in Medicaid for all 12 months and had at least 1 Medicaid claim for HU were included in the calculation of the HU utilization summary statistics. There were no HU Medicaid claims in the $65+$-year age group, thus they were excluded from the analysis. Logistic regression models were used to evaluate participant factors' influence on comanagement and HU treatment adherence (good vs fair or poor). Both models were conditional on age, gender, rural residence, and months enrolled in the CCNC network. A regression analysis including primary care and hematology visits as main effects with their interaction (comanagement) were added as predictors in the HU adherence model. For each outcome (comanagement and HU adherence), an area under the curve-receiver operating characteristic curve (AUC-ROC) was created. AUC-ROC provides an estimate of how capable the model is of distinguishing between the outcomes. The higher the AUC the better the model is at predicting good adherence versus fair or poor adherence. When $\mathrm{AUC}=0.5$, the model does not distinguish between levels of adherence.

\section{Results}

The participants in the sample were majority female $(56.82 \%)$, lived in metropolitan areas $(76.19 \%)$ and had a mean age of 22.87 years old $(\mathrm{SD}=16.41)$, see Table 1 . Table 3 displays the summary of utilization of acute care and outpatient services of the sample.

\section{ED and Hospital Utilization}

Of the 6834 total ED encounters, $70.95 \%$ of the total sample had an ED encounter during the 12month study period. There was a mean of 3.34 $(\mathrm{SD}=7.51)$ and median of $1(\mathrm{IQR}=0$ to 4$) \mathrm{ED}$ encounters per patient for the sample. Those who were 18 to 30 years old had the highest mean and median ED encounters per patient $(5.22 ; \mathrm{SD}=$ 9.38 and 2; IQR, 1 to 6). The 31-to-45-year-old group had the second most, with $5.20(\mathrm{SD}=12.15)$ total ED encounters. The percentage of the sample with an ED re-encounter within 7, 14, and 30 days was also highest among the 18-to-30-year-old group $(30.91 \%, 35.20 \%$, and $42.64 \%$ ) followed by those 31 to 45 years old $(20.49 \%, 30.36 \%$, and $36.02 \%)$, respectively. The mean EDR was highest among 18-to-30-year-old patients (0.35) and $44.69 \%$ of this age group had an EDR of 0.33 or greater. In the 31-to-45-year-old age group, the mean EDR was 0.27 and $34.01 \%$ had an EDR of 0.33 or greater. The overall sample had a mean of $1.32(\mathrm{SD}=2.78)$ hospitalizations/patient. The 18 to-30-year-old age-group also had the highest mean total hospitalizations $(2.26, \mathrm{SD}=3.91)$ and mean rehospitalizations within $7(0.16$; $\mathrm{SD}=0.78)$, 


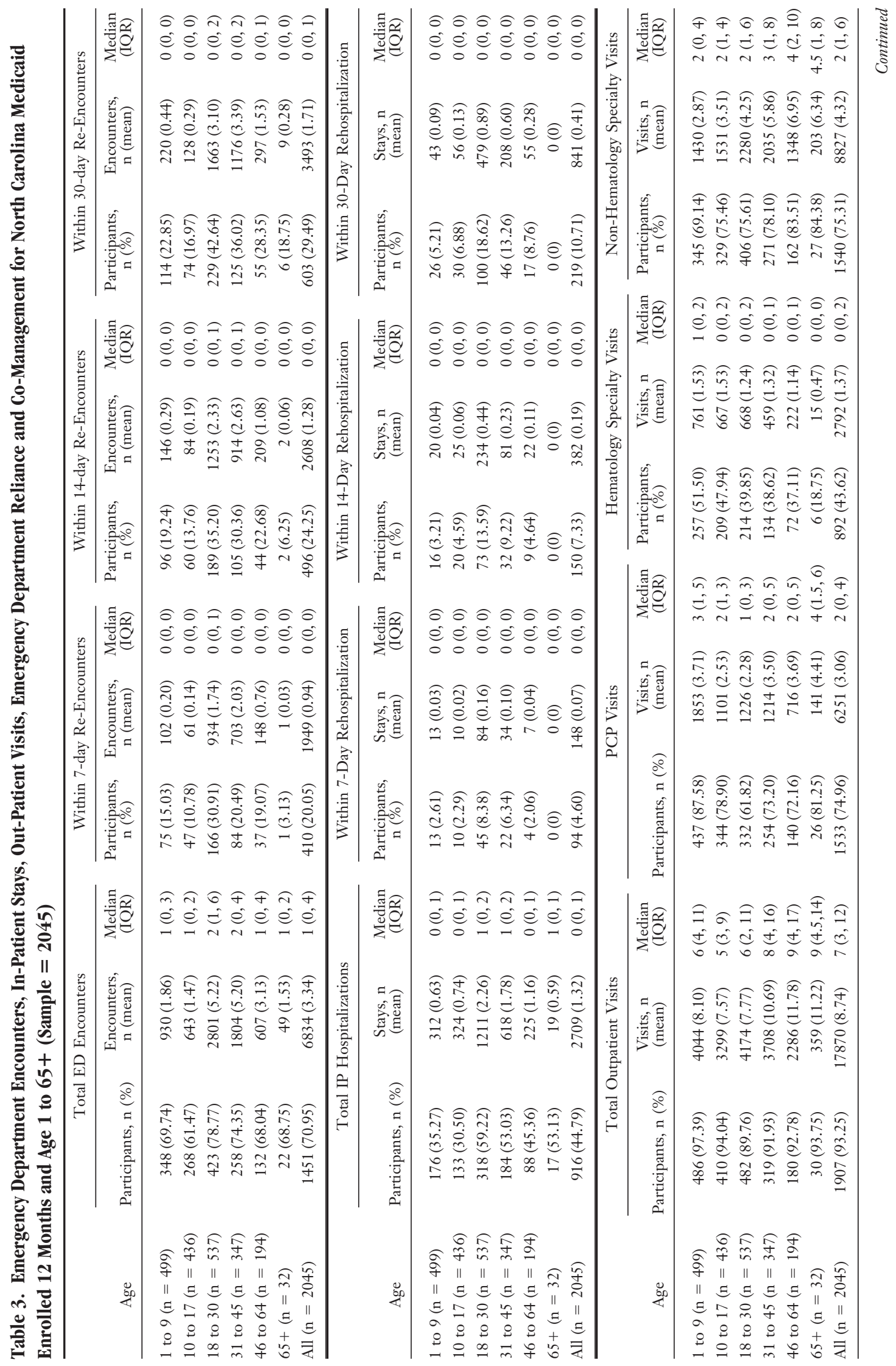


$14(0.44 ; \mathrm{SD}=1.78)$, and $30(0.89 ; \mathrm{SD}=2.97)$ days. The 31-to-45-year-old age group had the second most hospitalizations/patient and rehospitalizations (Table 3).

\section{Outpatient Visits and Comanagement}

The 46-to-64-year-old and the oldest (65+ years) of the sample had the highest median number of total outpatient visits (9 each), as well as nonhematology specialty visits (4 and 4.5), respectively. The youngest ( 1 to 9 years old) and the oldest $(65+$ years) had the highest median number of PCP visits ( 3 and 4 , respectively). Participants that were age 1 to 9 years had the highest median number of hematology visits. ${ }^{1}$ Overall, there were a large total number of nonhematology specialist visits: 8827 (Table 2). Outpatient acute care visits, PA and NP visits accounted for $60 \%$ of the total number of nonhematology specialist visits. Only $34.82 \%$, however, of the study sample met our definition of being comanaged. Comanagement was higher in the 1-to-9-year-old (44.88\%) and 10-to-17-yearold groups $(39.22 \%)$ versus the 31-to-45-year $(30.26 \%)$ and $65+$-year $(18.75 \%)$ age groups, see Table 3. Age had the greatest influence (AUC = 0.599 ) on whether or not a patient was comanaged, whereas, gender, months enrolled in CCNC, and residence had very little predictive influence on comanagement (Figure 1).

\section{HU Utilization}

A third of the sample (32.24\%) had at least $1 \mathrm{HU}$ prescription during the study period (Table 4). Those who were 1 to 9 years old had the highest median number of days supplied (221; range, 21 to 750 ), the least median days between breaks in HU treatment (14.21; range, 0 to 318), and the longest duration of $\mathrm{HU}$ treatment days (median, 340; range, 0 to 364). Those who were 18 to 30 years old had the lowest number of median days supplied (110; range, 4 to 366) and the most median days between treatment (49.3; range, 0 to 337). The 1-to-9-year-olds also had the highest number of patients classified as good HU adherence (47.50\%) and conversely the lowest classified as poor $\mathrm{HU}$ adherence $(37.50 \%)$. In contrast, the 18-to-30year-old age group had the lowest good HU adherence $(18.03 \%)$ and the highest poor HU adherence $(69.40 \%)$ in the sample. The $31-$ to- 45 yearold age groups had the next lowest good HU adherence $(20.93 \%)$ and next highest poor HU 
Figure 1. Area under the curve-receiver operating characteristics (AUC-ROC) curve for comanagement. Performance of predictor measures and a combined model including age, gender, residency, and months enrolled in Community Care of North Carolina (CCNC) for comanagement with area under the curve values for each.

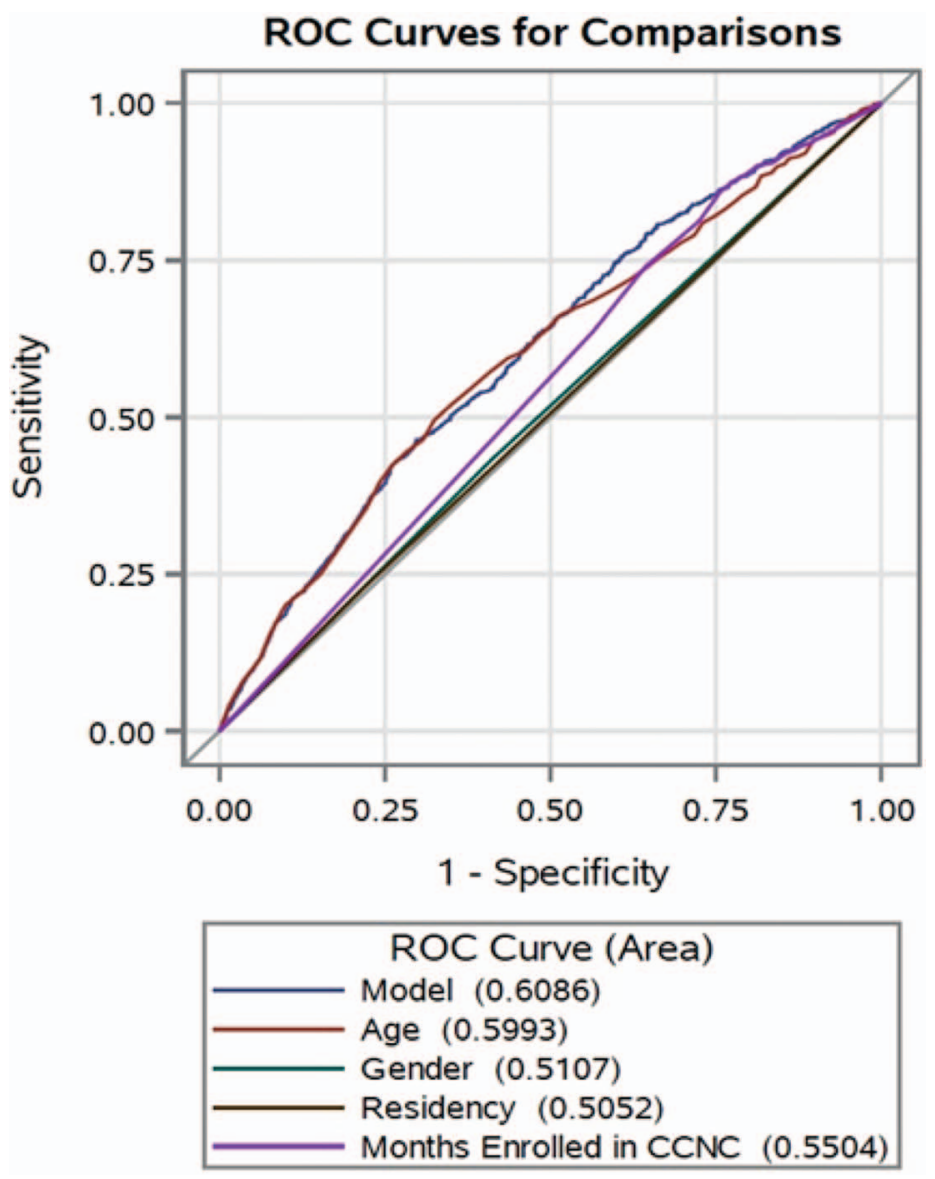

adherence $(60.47 \%)$. Age was the strongest predictive factor of good $\mathrm{HU}$ adherence (AUC $=0.6503$ ). Prediction by comanagement was minimal with an $\mathrm{AUC}=0.5615$, but it was greater than the prediction of primary care only (AUC $=0.5481$ ) or hematology care only (AUC $=0.5481$ ) (Figure 2). Gender, residency, and number of months enrolled in CCNC had little influence on HU adherence.

\section{Discussion}

Our study revealed high health service utilization and low rates of HU adherence, which are consistent with prior studies of SCD health care utilization. ${ }^{16,25,35-38} \mathrm{We}$ also found, however, a strikingly low rate of comanagement between the PCP and SCD specialist, simply defined as 1 visit to both a PCP and hematologist. Furthermore, we noted high utilization of additional services by nonhematologist specialist and significant variations in $\mathrm{HU}$ adherence by age group.

\section{ED Encounters and Hospitalization}

Prior national assessments of ED encounters in 1 year were estimated to be 232,381 and primarily by adult patients $(81 \%$ by adults, $19 \%$ by those $<18$ years). ${ }^{2}$ Similarly, our sample revealed 18 to-30-year-old and 31-to-45-year-old age groups had the highest rate of ED encounters, with close to three quarters of those age groups having at least $1 \mathrm{ED}$ encounter. This rate was lower than prior rates of up to $90 \%$ reported by Brousseau et $\mathrm{al}^{4}$ In the $<18$-year-old group, our sample had a lower ED encounter rate $(65.88 \%)$ compared with the national estimate of $67 \% .{ }^{38}$ In addition, previous studies have highlighted the highest EDR among the patients transitioning from pediatrics to adult medical care with an associated high health care cost. ${ }^{39}$ Our sample also highlighted poor transition to adult medical care with a significant percentage of 18-to-30-year-old patients ( $44.69 \%$ of the sample) having greater than 


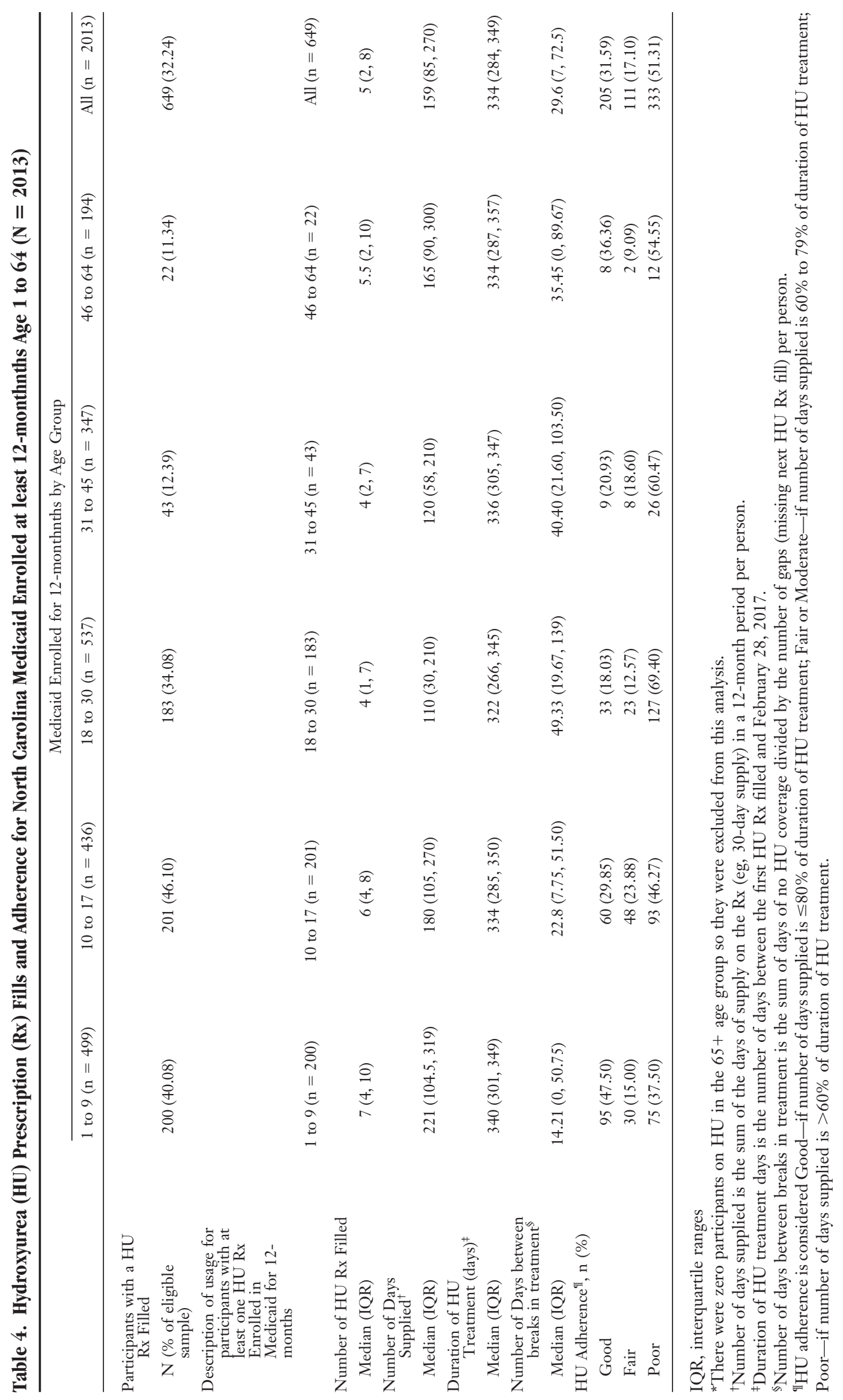


Figure 2. Performance of predictor measures and a combined model including Primary Care visit alone, Hematology visit alone, Co-management, age, gender, residency and months enrolled in Community Care of North Carolina (CCNC) for good versus fair or poor hydroxyurea adherence with area under the curve values for each.

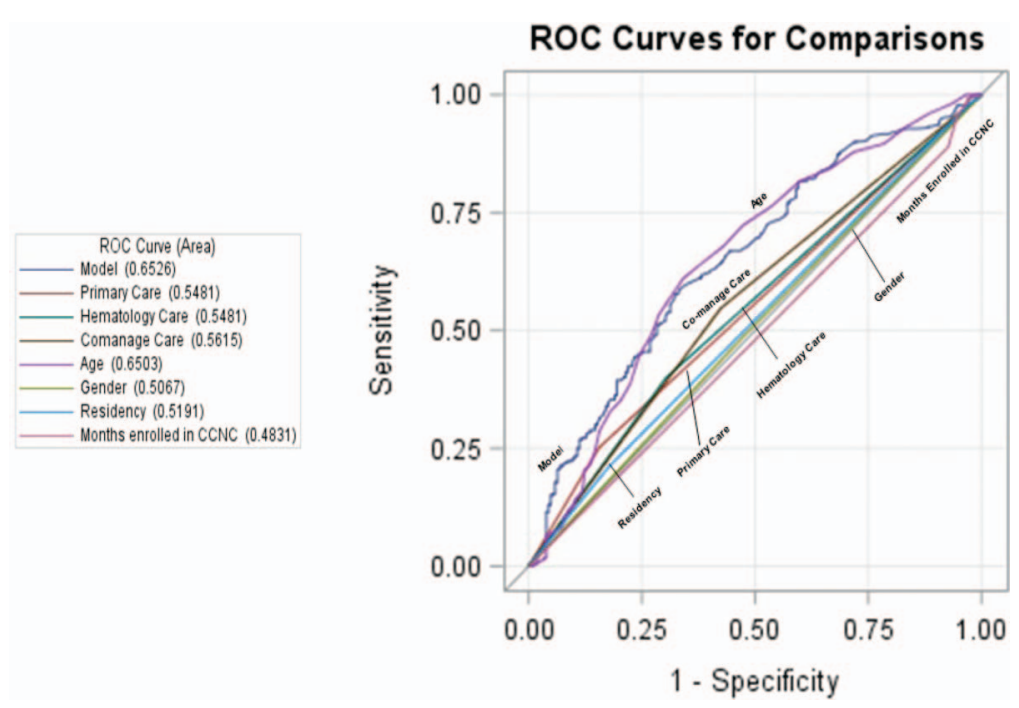

0.33 EDR, which indicates a high reliance on the ED. ${ }^{17}$

Patients with SCD are frequently admitted to the hospital for further pain control after initially being seen in the ED, supported by our findings that almost half of our sample were hospitalized during the study period. Furthermore, SCD has a higher rehospitalization rate than other chronic diseases such as heart failure and diabetes and rehospitalization is a measure of quality of care related to hospitalization. ${ }^{40}$ A significant contributor to health care costs in the chronically ill is 30-day rehospitalization rates, which may reflect the lack of access and quality of ambulatory care for patients with SCD. $2,37,41,42$ We found 7-, 14-, and 30-day rehospitalization rates were lower than prior findings (5\% to $16 \%)^{2,40}$ These lower rates may be due to state-based efforts by CCNC to reduce hospital admissions and readmissions, variations in access to care and insurance benefits by state and previous studies performing analysis on data over a decade ago. Risk factors for rehospitalizations such as age, (particularly the age at transition from pediatric to adult care) and having public health insurance have been previously identified. ${ }^{43}$ Our study supports prior findings indicating a spike in utilization that coincides with the age of transition from pediatric to adult SCD care and high utilization in a sample of NC Medicaid enrollees. Moreover, it indicates a continued need to develop interventions for SCD patients and providers that will improve care throughout the care transition period in this population. Finally, a lack of follow-up care with the PCP or hematologist has also been consistently reported as an important factor associated with rehospitalizations and return to the ED within 30 days of discharge. ${ }^{35,37,40,43,44}$

\section{Outpatient Visits}

In addition to evaluating PCP visits and hematology visits, our study included data on the number of outpatient visits with various specialists. We found a large number of nonhematology specialty visits, many by PAs and NPs, and agerelated differences in the types of outpatient services utilized. To the best of our knowledge, we are the first group to report this level of complex outpatient care and the use of multiple specialty services by SCD patients. This important finding has implications for care coordination. Use of patient navigators may be 1 intervention to assist patients with the high number of specialists and associated appointments required to manage SCD. ${ }^{45}$ Two projects funded by Patient Centered Outcomes Research Institute (PCORI) are currently evaluating the use of community health workers and peer mentoring to improve the transition period for emerging adults with SCD. ${ }^{46,47}$ These projects hope to generate evidence that will support the routine use of some type of support systems necessary to navigate the complex health care needs for individuals with SCD. 
There was little difference between the percentages of enrollees that had a PCP visit and a nonhematology specialist, although the total and mean number nonhematology specialist visits exceeded the total and mean number of PCP visits. This demonstrates the wide variety and high frequency of specialty care requirements for this population. The 1-to-17-year-old sample age groups had similar total outpatient visit rates to the $18+$-year age groups. Prior studies have reported a higher number of mean outpatient visits (12.6 vs 7.9 in our sample) for Medicaid-enrolled children. ${ }^{48} \mathrm{How}_{-}$ ever, there was a downward trend in the rate of hematology specialists visits in older SCD age groups. This trend was reversed in the nonhematology specialist visits, which were lowest in the youngest age group and highest in the oldest age group. Studies of SCD patients have previously shown that the absence of a PCP and missing or forgetting outpatient visits were associated with both hospitalizations and rehospitalizations of SCD patients. ${ }^{35,37}$ The effect of nonhematologist specialty visits on $\mathrm{ED}$ or inpatient health service utilization, in contrast, has not been reported. Information on the type of services provided by nonhematology specialists and the mechanisms (eg, referral processes) used by patients to access these services are needed. Service delivery may be influenced by restrictions in advanced practice provider practice, which vary by state. Patterns of outpatient specialist utilization are needed. This includes nonhematology specialists visits, before ED and hospitalizations for common complaints such as pain, as this is the most common reason for SCD patient hospitalization, is complex and difficult to manage. ${ }^{35,36,49,50}$ These findings support the need for alternative care models. However, models such as the patient- centered medical home $(\mathrm{PCMH})$ care model have been difficult to implement and for patients to access. ${ }^{7,51}$ A recent national survey of 1060 family practice physicians, found that only $20 \%$ reported being comfortable with overall management of SCD. ${ }^{13}$ However, $80 \%$ of respondents indicated they would be willing to comanage pediatric patients, and $68 \%$ reported they would be willing to comanage adult patients. ${ }^{13}$

\section{Comanagement}

It has been previously identified that there is a need to improve comanagement between specialists and PCPs for chronic diseases. In a large survey of 702 primary care practices, only $27 \%$ of primary care patients with chronic diseases were comanaged, despite evidence that comanagement can improve care of chronically ill patients. ${ }^{52}$ For example, comanagement by nephrologists and PCPs has been found to improve the PCP's ability to identify chronic kidney disease, referral to nephrologists, execution of comanagement plans, and improved monitoring of anemia and metabolic bone disease. ${ }^{53,54}$ Comanagement between rheumatology and primary care has also been suggested to improve management of patients with rheumatoid arthritis and cardiovascular disease. ${ }^{55}$ Our sample rate of comanagement was $34.82 \%$, but varied by age group. Comanagement was lower in the 18and-older age groups and age also contributed the most to our comanagement prediction model. This finding, along with the high number of nonhematology specialist visits in adults suggest a need to promote comanagement of SCD patients to a wider group of providers including PAs, NPs and other specialists such as obstetrician/gynecologists that have not been considered part of usual care for SCD patients. Similar to other chronic diseases, a comanagement model using a combination of a PCP and a hematology specialist to manage the care of SCD patients could potentially improve SCD quality of care by reducing disease complications and high acute care utilization. For example, comanagement models of care could specifically focus on increasing the rate of prescription and use of $\mathrm{HU}$, which is often under prescribed and the mainstay of therapy for SCD.

\section{HU Prescription Fills and Adberence}

$\mathrm{HU}$ has been shown to reduce the frequency of pain episodes, acute chest syndrome, need for red blood cell transfusions, hospitalizations, and mortality. ${ }^{10,56}$ Reported HU adherence rates vary widely depending on the assessment method used and the sample size. ${ }^{57-60}$ Although there is no perfect measurement of adherence, HU pharmacy refills have been used to identify SCD patients at risk for poor response due to nonadherence. ${ }^{60}$ Using Medicaid HU prescription claims, we found only a third of patients were classified as having good HU adherence, which was similar to the rate reported in a prior study (35\%) of NC Medicaid enrollees, using prescription claims data to obtain medication possession ratio as a measure of adherence. ${ }^{20} \mathrm{Fac}-$ tors leading to poor adherence include patient neg- 
ative perceptions about benefits of $\mathrm{HU}$, adverse symptoms, and poor emotional response to SCD. ${ }^{56,61,62}$ Age has been shown to have a significant effect on HU adherence, with older age being associated with poorer adherence. ${ }^{57} \mathrm{We}$ found a similar trend, with increasing age and decreasing number of participants with a filled HU prescription, the number of HU prescriptions filled, number of days supplied, and adherence. HU adherence in the $65+$-year age group was excluded from our analysis because they had no HU prescription fills. Age was more highly associated with good versus fair or poor HU adherence than the proposed statistical model. However, comanagement was associated with HU adherence, despite low overall rates of comanagement in our sample. This finding warrants further analysis of the relationship of comanagement to $\mathrm{HU}$ adherence, which may in turn influence ED and inpatient utilization.

\section{Study Limitations}

There were several limitations of our study. Our study only included Medicaid enrollees with SCD, a group that has been found to have higher rates of health service utilization in several other studies. ${ }^{2,4,36,63-65}$ Only Medicaid claims from 2016 to 2017, after the initiation of the Patient Protection and Affordable Care Act (ACA) were used in our study. Although NC did not expand Medicaid coverage, studies on ED and outpatient health service utilization after the ACA went into effect have varied greatly between states. ${ }^{66-68}$ Variations in utilization may also result from between state differences in the number of new Medicaid enrollees, coverage limits and the number of years since expansion occurred. Future comparisons of health service utilization that considers these payer differences (Medicaid expanded and not expanded) by state would provide a more robust understanding of utilization in the SCD population.

Differences in the number of SCD-related ED visits have been noted depending on the volume and proximity of the ED to metropolitan areas. ${ }^{2}$ Our data did not include the location of the ED where the encounter occurred, so this level of analysis was excluded from our study. In addition, the study observation period was shorter, (12 months) in our study compared with other studies that have included more than 2 years of utilization data. ${ }^{2,4,63,69}$ The episodic nature of SCD, including intermittent periods of very high service utilization followed by periods of lower service utilization may have led to over- or underrepresentation of data during our 12-month study period. We were also unable to classify claims with no rendering provider information. These claims were categorized into an unidentifiable (null) category, but likely caused an underrepresentation of another nonhematology specialist category. We were also unable to determine the practice type of PAs and NPs, specifically whether they were SCD specialists or primary care. In addition, we were unable to review medical records to describe the type of comanagement that occurred between the specialist and PCP, the type of care provided by the PCPs, or "who" prescribed HU. This article reports our baseline data, before dissemination of the NHLBI evidence based guidelines and we cannot yet comment on how they will affect practice.

\section{Conclusion}

In our study, age was the most important factor in predicting comanagement and HU adherence and there were notable age-related differences in health care utilization. As in prior studies, the age at which $\mathrm{ED}$ and inpatient use increases, coincides with the period of transition from pediatric to adult care. ${ }^{16,26,70}$ Increased utilization from acute care services has been described in several studies of pediatric to adult care transition. ${ }^{1,22}$ Our study further supports the need for increased focus on acute care utilization in the 18-to-45-year-old age group and considerations for improved care transition interventions. ${ }^{71}$ Interventions that improve $\mathrm{HU}$ adherence are of particular importance in reducing acute care utilization. Importantly, we found comanagement is associated with HU adherence. Further studies of the influence of comanagement on known drivers of high SCD acute care utilization such as acute pain episodes are needed, as well as studies that identify the frequency and components of comanagement needed to increase adherence and reduce acute care utilization. While we were able to report preliminary data on outpatient utilization including utilization of nonhematology specialist, we did not report specifics such as procedures or the chief complaint associated with these visit (eg, pain related) or include nonhematology specialist utilization in our comanagement or HU adherence models. Future research that considers nonhematology specialist in understanding of SCD health service utilization is also needed. 
To see this article online, please go to: http://jabfm.org/content/ 33/1/91. full.

\section{References}

1. Hassell KL. Population estimates of sickle cell disease in the U.S. Am J Prev Med 2010;38:S512-S521.

2. Lanzkron S, Carroll CP, Haywood C Jr. The burden of emergency department use for sickle-cell disease: an analysis of the national emergency department sample database. Am J Hematol 2010;85:797-9.

3. Elixhauser A, Steiner CA. Readmissions to U.S. hospitals by diagnosis, 2010. Rockville, MD: Agency for Healthcare Research and Quality; August 2013. Statistical Brief \#153.

4. Brousseau DC, Owens PL, Mosso AL, Panepinto JA, Steiner CA. Acute care utilization and rehospitalizations for sickle cell disease. JAMA 2010;303:1288-94.

5. Tanabe P, Artz N, Mark Courtney D, et al. Adult emergency department patients with sickle cell pain crisis: a learning collaborative model to improve analgesic management. Acad Emerg Med 2010;17: 399-407.

6. Tanabe P, Hafner JW, Martinovich Z, Artz N. Adult emergency department patients with sickle cell pain crisis: results from a quality improvement learning collaborative model to improve analgesic management. Acad Emerg Med 2012;19:430-8.

7. Raphael JL, Oyeku SO. Sickle cell disease pain management and the medical home. Washington, DC: Hematology American Society of Hematology Education Program 2013;2013:433-8.

8. Aljuburi G, Phekoo KJ, Okoye NO, et al. Patients' views on improving sickle cell disease management in primary care: focus group discussion. JRSM Short Rep 2012;3:84.

9. Lunyera J, Jonassaint C, Jonassaint J, Shah N. Attitudes of primary care physicians toward sickle cell disease care, guidelines, and comanaging hydroxyurea with a specialist. J Prim Care Community Health 2017;8:37-40.

10. Yawn BP, Buchanan GR, Afenyi-Annan AN, et al. Management of sickle cell disease: summary of the 2014 evidence-based report by expert panel members. JAMA 2014;312:1033-48.

11. Adams-Graves P, Bronte-Jordan L. Recent treatment guidelines for managing adult patients with sickle cell disease: challenges in access to care, social issues, and adherence. Expert Rev Hematol 2016;9: 541-52.

12. Whiteman LN, Haywood C Jr, Lanzkron S, Strouse JJ, Feldman L, Stewart RW. Primary care providers' comfort levels in caring for patients with sickle cell disease. South Med J 2015;108:531-6.

13. Mainous AG III, Tanner RJ, Harle CA, Baker R, Shokar NK, Hulihan MM. Attitudes toward management of sickle cell disease and its complications: a national survey of academic family physicians. Anemia $2015 ; 853835$.
14. Tilson EC. Dissemination and Adoption of guidelines: the experience of community care of North Carolina. N C Med J 2015;76:251-5.

15. North Carolina Institute of Medicine. Understanding Medicaid in North Carolina Primer. 2018. Available from: http://nciom.org/ wp-content/uploads/2018/01/NC_Medicaid_ CHIP_Primer.pdf. Accessed September 27, 2018.

16. Blinder MA, Duh MS, Sasane M, Trahey A, Paley C, Vekeman F. Age-related emergency department reliance in patients with sickle cell disease. J Emerg Med 2015;49:513-522 e511.

17. Kroner EL, Hoffmann RG, Brousseau DC. Emergency department reliance: a discriminatory measure of frequent emergency department users. Pediatrics 2010;125:133-8.

18. Centers for Medicare and Medicaid Services. Crosswalk Medicare Provider/Supplier to Healthcare Provider Taxonomy. 2018. Available from: https://data. cms.gov/Medicare-Enrollment/CROSSWALK-MEDICARE-PROVIDER-SUPPLIER-to-HEALTHCARE/ j75i-rw8y.

19. Walsh KE, Cutrona SL, Kavanagh PL, et al. Medication adherence among pediatric patients with sickle cell disease: a systematic review. Pediatrics 2014;134:1175-83.

20. Candrilli SD, O'Brien SH, Ware RE, Nahata MC, Seiber EE, Balkrishnan R. Hydroxyurea adherence and associated outcomes among Medicaid enrollees with sickle cell disease. Am J Hematol 2011;86: 273-7.

21. Andemariam B, Owarish-Gross J, Grady J, Boruchov D, Thrall RS, Hagstrom JN. Identification of risk factors for an unsuccessful transition from pediatric to adult sickle cell disease care. Pediatr Blood Cancer 2014;61:697-701.

22. Kayle M, Docherty SL, Sloane R, et al. Transition to adult care in sickle cell disease: a longitudinal study of clinical characteristics and disease severity. Pediatr Blood Cancer 2019;66:e27463.

23. McClish DK, Smith WR, Levenson JL, et al. Comorbidity, pain, utilization, and psychosocial outcomes in older versus younger sickle cell adults: The PiSCES project. Biomed Res Int 2017;2017: 4070547.

24. Quinn CT, Rogers ZR, McCavit TL, Buchanan GR. Improved survival of children and adolescents with sickle cell disease. Blood 2010;115:3447-52.

25. Brousseau DC, Panepinto JA, Nimmer M, Hoffmann RG. The number of people with sickle-cell disease in the United States: national and state estimates. AM J Hematol 2010;85:77-8.

26. Steiner CA, Miller JL. Sickle cell disease patients in U.S. hospitals, 2004. HCUP Statistical Brief \#21 2006. Available from: http://www.hcup-us.ahrq.gov/ reports/statbriefs/sb21.pdf. Accessed December, 2018. 
27. Fillingim RB, King CD, Ribeiro-Dasilva MC, Rahim-Williams B, Riley JL 3rd. Sex, gender, and pain: a review of recent clinical and experimental findings. J Pain 2009;10:447-85.

28. Bartley EJ, Fillingim RB. Sex differences in pain: a brief review of clinical and experimental findings. Br J Anaesthesia 2013;111:52-8.

29. Sorge RE, Strath LJ. Sex differences in pain responses. Curr Opin Physiol 2018;6:75-81.

30. McClish DK, Levenson JL, Penberthy LT, et al. Gender differences in pain and healthcare utilization for adult sickle cell patients: The PiSCES Project. J Women's Health 2006;15:146-54.

31. Udezue E, Girshab AM. Differences between males and females in adult sickle cell pain crisis in eastern Saudi Arabia. Ann Saudi Med 2004;24:179-82.

32. Haque A, Telfair J. Socioeconomic distress and health status: the urban-rural dichotomy of services utilization for people with sickle cell disorder in North Carolina. J Rurual Health 2000;16:43-55.

33. Asnani MR, Knight Madden J, Reid M, Greene LG, Lyew-Ayee P. Socio-environmental exposures and health outcomes among persons with sickle cell disease. PLoS One 2017;12:e0175260.

34. United States Department of Agriculture. Metropolitan statistical areas metropolitan divisions micropolitan statistical areas and combined statistical areas and guidance on uses of the delineations of these areas. 2013. Available from: https://obamawhitehouse.archives.gov/ sites/default/files/omb/bulletins/2013/b-13-01.pdf. Accessed September 26, 2018.

35. Cronin RM, Hankins JS, Byrd J, et al. Risk factors for hospitalizations and readmissions among individuals with sickle cell disease: results of a U.S. survey study. Hematology 2019;24:189-98.

36. Benenson I, Jadotte Y, Echevarria M. Factors influencing utilization of hospital services by adult sickle cell disease patients: a systematic review. JBI Database System Rev Implement Rep 2017;15:765-808.

37. Brodsky MA, Rodeghier M, Sanger M, et al. Risk factors for 30-day readmission in adults with sickle cell disease. Am J Med 2017;130:601; e609-e615.

38. Lanzkron S, Little J, Field J, et al. Increased acute care utilization in a prospective cohort of adults with sickle cell disease. Blood Advances 2018;2:2412-7.

39. Blinder MA, Vekeman F, Sasane M, et al. Agerelated emergency department reliance and healthcare resource utilization in patients with sickle cell disease. Blood 2012;120(475).

40. Leschke J, Panepinto JA, Nimmer M, Hoffmann RG, Yan K, Brousseau DC. Outpatient follow-up and rehospitalizations for sickle cell disease patients. Pediatr Blood Cancer 2012;58:406-9.

41. Hemker BG, Brousseau DC, Yan K, Hoffman RG, Panepinto JA. When children with sickle-cell disease become adults: lack of outpatient care leads to increased use of the emergency department. Am J Hematology 2011;86:863-5.
42. Frei-Jones MJ, Field JJ, DeBaun MR. Risk factors for hospital readmission within 30 days: a new quality measure for children with sickle cell disease. Pediatr Blood Cancer 2009;52:481-5.

43. Ballas SK, Lusardi M. Hospital readmission for adult acute sickle cell painful episodes: frequency, etiology, and prognostic significance. Am J Hematol 2005;79:17-25.

44. Field TS, Ogarek J, Garber L, Reed G, Gurwitz JH. Association of early post-discharge follow-up by a primary care physician and 30-day rehospitalization among older adults. J Gen Intern Med 2015;30:565-71.

45. Rollins M, Milone F, Suleman S, Vojvoda D, Sgro M, Barozzino T. Patient navigators: mapping the route toward accessibility in health care. Paediatrics Child Health 2019;24:19-22.

46. Rubin DM. Community health worker and mobile health programs to help young adults with sickle cell disease transition to using adult healthcare services: the COMETS STudy. 2017. Available from: https:// www.pcori.org/research-results/2017/communityhealth-worker-and-mobile-health-programs-helpyoung-adults-sickle. Accessed March 23, 2019.

47. Osunkwo I. Comparitive effectiveness of peer mentoring versus structured education-based transition programming for the management of care transitions in emerging adults with sickle cell disease. 2017. Available from: https://www.pcori.org/ research-results/2017/comparative-effectivenesspeer-mentoring-versus-structured-educationbased. Accessed March 23, 2019.

48. Mvundura M, Amendah D, Kavanagh PL, Sprinz PG, Grosse SD. Health care utilization and expenditures for privately and publicly insured children with sickle cell disease in the United States. Pediatr Blood Cancer 2009;53:642-6.

49. Cronin RM, Hankins JS, Byrd J, et al. Modifying factors of the health belief model associated with missed clinic appointments among individuals with sickle cell disease. Hematology 2018;23:683-91.

50. Carroll CP, Cichowitz C, Yu T, et al. Predictors of acute care utilization and acute pain treatment outcomes in adults with sickle cell disease: The role of non-hematologic characteristics and baseline chronic opioid dose. Am J Hematol 2018;93: 1127-35.

51. Raphael JL, Rattler TL, Kowalkowski MA, Mueller BU, Giordano TP. The medical home experience among children with sickle cell disease. Pediatr Blood Cancer 2013;60:275-80.

52. Larochelle JL, Feldman DE, Levesque JF. The primary-specialty care interface in chronic diseases: patient and practice characteristics associated with comanagement. Healthcare Policy 2014;10:52-63.

53. Samal L, Wright A, Waikar SS, Linder JA. Nephrology co-management versus primary care solo management for early chronic kidney disease: a retro- 
spective cross-sectional analysis. BMC Nephrol 2015;16:162.

54. Haley WE, Beckrich AL, Sayre J, et al. Improving care coordination between nephrology and primary care: a quality improvement initiative using the renal physicians association toolkit. Am J Kidney Dis 2015;65:67-79.

55. Bartels CM, Roberts TJ, Hansen KE, et al. Rheumatologist and primary care management of cardiovascular disease risk in rheumatoid arthritis: patient and provider perspectives. Arthritis Care Res (Hoboken) 2016;68:415-23.

56. Brandow AM, Panepinto JA. Hydroxyurea use in sickle cell disease: the battle with low prescription rates, poor patient compliance and fears of toxicities. Expert Rev Hematol 2010;3:255-60.

57. Loiselle K, Lee JL, Szulczewski L, Drake S, Crosby LE, Pai AL. Systematic and meta-analytic review: medication adherence among pediatric patients with sickle cell disease. J Pediatr Psychol 2016;41:406-18.

58. Patel NG, Lindsey T, Strunk RC, DeBaun MR. Prevalence of daily medication adherence among children with sickle cell disease: a 1-year retrospective cohort analysis. Pediatr Blood Cancer 2010;55: 554-6.

59. Heeney MM, Ware RE. Hydroxyurea for children with sickle cell disease. Hematol Oncol Clin North Am 2010;24:199-214.

60. Thornburg CD, Calatroni A, Telen M, Kemper AR. Adherence to hydroxyurea therapy in children with sickle cell anemia. J Pediatrics 2010;156:415-9.

61. Badawy SM, Thompson AA, Lai JS, Penedo FJ, Rychlik K, Liem RI. Adherence to hydroxyurea, health-related quality of life domains, and patients' perceptions of sickle cell disease and hydroxyurea: a cross-sectional study in adolescents and young adults. Health Qual Life Outcomes 2017;15:136.

62. Haywood C Jr, Beach MC, Bediako S, et al. Examining the characteristics and beliefs of hydroxyurea users and nonusers among adults with sickle cell disease. AM J Hematol 2011;86:85-7.

63. Carroll CP, Haywood C Jr, Fagan P, Lanzkron S. The course and correlates of high hospital utilization in sickle cell disease: evidence from a large, urban Medicaid managed care organization. Am J Hematol 2009;84:666-70.

64. Mayer ML, Konrad TR, Dvorak CC. Hospital resource utilization among patients with sickle cell disease. J Health Care Poor Underserved 2003;14: 122-35.

65. Yusuf HR, Atrash HK, Grosse SD, Parker CS, Grant AM. Emergency department visits made by patients with sickle cell disease: a descriptive study, 1999-2007. Am J Prev Med 2010;38:S536-S541.

66. Gingold DB, Pierre-Mathieu R, Cole B, Miller AC, Khaldun JS. Impact of the Affordable Care Act Medicaid expansion on emergency department high utilizers with ambulatory care sensitive conditions: a cross-sectional study. Am J Emerg Med 2017;35: 737-42.

67. Nikpay S, Freedman S, Levy H, Buchmueller T. Effect of the Affordable Care Act Medicaid expansion on emergency department visits: evidence from state-level emergency department databases. Ann Emerg Med 2017;70:215-225; e216.

68. Sommers BD, Blendon RJ, Orav EJ, Epstein AM. Changes in utilization and health among low-income adults after Medicaid expansion or expanded private insurance. JAMA Intern Med 2016;176:1501-9.

69. Ter-Minassian M, Lanzkron S, Derus A, Brown E, Horberg MA. Quality metrics and health care utilization for adult patients with sickle cell disease. J Natl Med Assoc 2019;111:54-61.

70. Jordan L, Swerdlow P, Coates TD. Systematic review of transition from adolescent to adult care in patients with sickle cell disease. J Ped Hematol Oncol 2013;35:165-9.

71. Minniti CP, Vichinsky E. Lifespan care in SCD: whom to transition, the patients or the health care system? Am J Hematol 2017;92:487-9. 